\title{
Revalidation of physicians in Canada: Are we passing the test?
}

$\mathrm{P}$ hysicians are ethically bound to maintain competence in their field as part of their professional accountability to the public. The Canadian Medical Association's Code of Ethics says it is the responsibility of physicians "to engage in lifelong learning to maintain and improve their professional knowledge, skills and attitudes."1 Despite this, no external verification of Canadian physicians' ongoing competence is required and, hence, the profession cannot prove to the public that it is ensuring the highest standards.

Currently, the processes for ensuring that physicians maintain their competence depend on the independent and heterogeneous regulatory decisions of each provincial College of Physicians and Surgeons. At present, 3 provinces (Saskatchewan, Ontario and Quebec) have mandated that physicians participate in an educational program to maintain their licence. Typically, this requirement is met by participation in the Royal College of Physicians and Surgeons' Maintenance of Certification program or the College of Family Physicians' Maintenance of Proficiency program. Although these programs address the right conceptual elements of maintaining competence, they are based on self-reporting and therefore lack rigour in holding physicians accountable. An alternative approach used in Alberta and Nova Scotia requires physicians to participate in a review process in which they are offered feedback from patients and peers about their performance. The program is designed to foster quality improvement, but it lacks an external standard for "passing." Moreover, the process is only feasible for primary care and larger specialties because it is hard to do peer review in specialties with few members.

Voices for change are now demanding a more transparent and accountable process to uphold professional standards. In 2007, a position paper by the Federation of Medical Regulatory Authorities of Canada stated that "all licensed physicians in Canada must participate in a recognized revalidation process in which they demonstrate their commitment to continued competent performance in a framework that is fair, relevant, inclusive, transferable and formative."2 It stated that the programs administered by the Royal College of Physicians and Surgeons and the College of Family Physicians provided a Canadian standards-based framework for professional development but that the programs lack evidence of whether physicians actually put their knowledge and skills into practice. Although the Federation of Medical Regulatory Authorities of Canada does not have the authority to implement changes, the broad support for this position paper from national medical organizations has put pressure on the provincial colleges to consider policy changes. Additionally, high-profile examples of serious breaches in medical practice standards by individual doctors, like the recent cases of pathology errors in New Brunswick and Newfoundland, raise legitimate media and public concerns about whether current scrutiny of physicians by their peers is sufficiently rigorous or whether external regulation is required. Furthermore, the bar is being raised elsewhere, while Canada is not keeping pace: other countries such as the United Kingdom and the United States have already implemented more demanding revalidation mechanisms than currently required by most Canadian provinces.

As a practising internist in Canada, I have participated in the Royal College's Maintenance of Certification program. Every year, I submit my credits for participating in continuing medical education activities, including attending lectures, answering clinical questions relevant to my practice and engaging in a self-assessment program. No one tests me to see what I have learned or whether I have put the knowledge into practice. In contrast, I recently participated in the American Board of Internal Medicine's Maintenance of Certification process and found it far more challenging and demanding. Since 1990, all specialists in the United States must recertify every 10 years to continue to call themselves a certified specialist. The process requires participation in 2 components that are absent in Canada: a practice-improvement exercise and a secure examination. The practice-improvement module includes collecting data on actual practice performance in a particular area (e.g., diabetes management), assessing the office organization that supports care, and surveying patients to understand their experience. These data are submitted to the American Board of Internal Medicine, and physicians receive feedback compared with established standards and their peers. Physicians must also submit a quality-improvement plan. The secure examination is a computerized multiple choice test of cognitive skills in the field of practice. To prepare for the secure exam portion, I used a knowledge selfassessment program to review all of general internal medicine. Both the practice improvement and the preparation for the examination required significantly more sweat equity than the Royal College's process. I studied for 4 months and was worried that I would fail. I would never have made the effort if not faced with an examination.

Should we all have to pass an examination at periodic intervals? Evidence shows that the public supports the idea of regular knowledge examination of physicians. One survey reported $87 \%$ of patients believe this should occur. ${ }^{3}$ Furthermore, there is evidence that scores on a test can be an indicator of performance. In Quebec, investigators found that family physicians' scores on their certification examination and Medical Council of Canada Qualifying Examination were related to provision of quality care after 4-7 years in practice. ${ }^{4}$ More recently, Holmboe and colleagues found that physi- 
cians' scores on the American Board of Internal Medicine's Maintenance of Certification examination was associated with higher rates of performance in care for Medicare patients. ${ }^{5}$ Although cognitive knowledge tested with examinations is not the only measure of competence, it is an important dimension of accurate diagnosis and clinical decisionmaking. Undoubtedly, there is a need for more research to understand the relation between revalidation and quality of care in practice and to explore the most effective methods to assess physicians' maintenance of skills, knowledge and attitudes.

Canadian physicians and the provincial colleges should implement revalidation for all physicians. The standards must include an external assessment of physician competence, rather than relying exclusively on self-assessment. Some form of rigorous external testing is needed to make physicians work to meet the bar. Although further evidence is needed to determine the best process of revalidation, the process should include an external assessment of both medical knowledge and the actual ability of physicians to implement quality care in their practice. A secure examination, like in the United States, could assess knowledge, and a practice review with input from peers and patients could assess actual performance. National standards should delineate the minimum requirements.

Physicians will inevitably have concerns about the implications of raising the bar, including fears of failure, the burden of preparing and the possible effect of losing some physicians who do not pass from the workforce. However, these concerns would likely be transient. In the United States, recertification programs were met with initial resistance from physicians, but revalidation is now the expectation of all new graduates. Ultimately, we must be able to assure our colleagues and the public that we are living up to our professional responsibility of self-regulation and protecting the public's trust in our health care system.

\section{Wendy Levinson MD}

Sir John and Lady Eaton Professor and Chair

Department of Medicine

University of Toronto

Toronto, Ont.

With the Editorial-Writing Team (Paul C. Hébert MD MHSc, Rajendra Kale MD, Matthew B. Stanbrook MD PhD, Barbara Sibbald BJ, Ken Flegel MDCM MSc and Amir Attaran LLB DPhil)

Competing interests: Wendy Levinson is chair-elect of the American Board of Internal Medicine. See www.cmaj.ca/misc/edboard.shtml for the EditorialWriting Team's statements.

\section{REFERENCES}

1. Canadian Medical Association. CMA Code of Ethics. Ottawa (ON): The Association; 2004. Available: http://policybase.cma.ca/PolicyPDF/PD04-06.pdf (accessed 2008 Aug 25)

2. Federation of Medical Regulatory Authorities of Canada Revalidation Working Group. Physician revalidation: maintaining competence and performance. Ottawa $(\mathrm{ON})$ : The Federation; 2007. Available: www.fmrac.ca/committees/documents /final_reval_position_eng.pdf (accessed 2008 Sept 9).

3. Brennan TA, Horwitz RI, Duffy FD, et al. The role of physician specialty board certification status in the quality movement. JAMA 2004;292:1038-43.

4. Tamblyn R, Abrahamowicz M, Dauphinee WD, et al. Association between licensure examination scores and practice in primary care. JAMA 2002;288:3019-26.

5. Holmboe ES, Wang Y, Meehan T, et al. Association between maintenance of certification examination scores and quality of care for medicare beneficiaries. Arch Intern Med 2008;168:1396-403. 